Edited 9 June 2010

\title{
Child Undernutrition in India
}

\author{
Raghav Gaiha \\ MIT and \\ University of Delhi
}

\author{
Raghbendra Jha \\ Australian National \\ University
}

Vani S. Kulkarni
Yale University

Vani S. Kulkarni
Yale University

All correspondence to:

Prof. Raghbendra Jha,

Australia South Asia Research Centre,

College of Asia and the Pacific

H.C. Coombs Building (09)

Australian National University,

Canberra, ACT 0200, Australia

Phone: + 6126125 2683; Fax: + 6126125 0443;

Email: r.jha@anu.edu.au 


\begin{abstract}
We have constructed a composite indicator of anthropometric failure (CIAF) that refines the Waterlow-3 tier classification, using a recent nation-wide household survey. The CIAF and its disaggregation into subcategories of undernourished 5 years old children reveal a grimmer story of child undernutrition than conventional anthropometric indicators do. Besides, simultaneous occurrence of anthropometric failures (e.g. stunting and underweight, and stunting, wasting and underweight) is pervasive. Our analysis of determinants of CIAF yields some new insights-specifically, the important role of food prices. Investigation of the links between different anthropometric failures and prevalence of infectious diseases (viz. Diarrhoea and acute respiratory infection), however, offers some justification for the disaggregated classification of undernourished children used here. Specifically, those with more than one failure were worse-off in this respect than children with no failure. There is a strong case for income growth together with food price stabilisation in curbing child undernutrition. Education has the desired effect but it is less strong than expected. Improvement in the quality of home environment makes a difference too but it is not conditional on income or wealth alone.
\end{abstract}

Key words: stunting, wasting, underweight, poverty, infectious diseases, and mortality JEL Classification: D12, D60, I10, I31 


\section{Child Undernutrition in India ${ }^{1}$}

\section{Introduction}

In recent years, there has been a growing realisation that poverty is multi-dimensional and money-metric indicators such as minimum income or expenditure cannot adequately capture all these dimensions. Attention has therefore shifted to other indicators such as health status that relate more closely to basic capabilities of individuals. An important point is that the correspondence between basic capabilities (e.g. to live a healthy and productive life) and level of income is often weak (Sen, 1985, 1999). It is therefore not surprising that a wide range of indicators including income/expenditure, health and education reflect a diverse pattern in India during the 1990s. In fact, as emphasised in a recent study, while most indicators have continued to improve during the 1990s, social progress has followed diverse patterns, ranging from accelerated progress in some fields to slowdown and even regression in others. ${ }^{2}$

Anthropometric measures of child malnutrition rely on height, weight, skin-fold thickness and age. The most commonly used measures of anthropometric failure are stunting (low height for age), wasting (low weight for height) and underweight (low weight for age). ${ }^{3}$ Stunting is an indicator of chronic undernutrition, attributable to prolonged food deprivation, and/or disease or illness; wasting is an indicator of acute undernutrition, caused by more recent food deprivation or illness; underweight is a composite indicator of both acute and chronic undernutrition. Until recently these indices were compared against an international reference population indicators collected in the United States by the National Centre for

\footnotetext{
${ }^{1}$ This study was funded by the British Government, under the Foresight Global Food and Farming Futures Project. It has benefited from the advice of L. Haddad, A. Venkatraman, Anil Deolalikar, Sonal Desai, S. Nandy, P. Svedberg and J.Murasko. The econometric analysis was carried out competently by Raj Bhatia and Manoj Pandey. We alone, however, are responsible for the views expressed here.

2 Besides, a more recent analysis (Deaton. and Dreze, 2009) shows that the decline in total calories' intake is more or less the same for the rich and poor. But cereal calories decline is much faster among the rich. In fact, per capita calorie intake has fallen at all levels of per capita household expenditure. Why people at higher expenditure levels have reduced their consumption of calories over time is perhaps not so hard to understand but why those at the lower end of the expenditure have done so is intriguing. A somewhat stunning result is that if we go by the norms of per capita calorie norms of 2100 for urban areas and 2400 for the rural, the proportions of calorie deficient populations in the urban and rural areas have risen over the period 1993 to 2004 - from about 58 per cent to about 64 per cent in urban areas, and from about 71 per cent to about 80 per cent in rural areas. As a result, at the all-India level, the calorie deficient population rose from about 68 per cent to about 76 per cent. This further illustrates the disconnect between income and nutritional deprivation.

${ }^{3}$ For an exposition, we draw upon Nandy et al. (2005), and Behrman and Deolalikar (1988).
} 
Health Statistics (NCHS). ${ }^{4}$ Children whose measurements fall below -2z scores of the reference population median are considered undernourished: stunted, wasted or underweight. Those with measurements below -3z scores are considered severely undernourished.

An important feature of these indicators is the overlap between them: some children who are stunted will also have wasting and/or be underweight; some children who have wasting will also be stunted or and/or underweight. So there is a need for a more comprehensive measure of child undernutrition. Such a measure is proposed below and measured with a recent household survey conducted jointly by University of Maryland and National Council of Applied Economic Research, using the recent WHO norms (2006).

In a not-so-recent study, Svedberg (2000) emphasises that the conventional indices of anthropometric failure are not sufficient for measuring the overall prevalence of child undernutrition. Since being underweight (having low weight for age) is a product of stunting and wasting and not their sum, it misses some children who are considered undernourished by the other indices, so producing an underestimate. So if children with wasting, stunting or who are underweight are all considered undernourished, a new aggregate indicator is needed that encompasses all undernourished children, be they wasted and/or stunted and /or underweight. This index is refereed to as a composite index of anthropometric failure (CIAF).

\section{Data}

Our analysis is based on a nationwide household survey, India Human Development Survey 2005 (IHDS), conducted jointly by University of Maryland and National Council of Applied Economic Research (NCAER).

IHDS covers over 41000 households residing in rural and urban areas, selected from 33 states. ${ }^{5}$ The sample comprises 384 districts out of a total of 593 identified in 2001 census. Villages and urban blocks constituted the primary sampling unit from which households were selected.

The rural sample contains about half the households that were interviewed initially by NCAER in 1993-94 in a survey entitled Human Development Profile of India-HDPI-and the other half of the sample households was drawn from both districts surveyed in HDPI as well as from districts located in the states and union territories not covered in HDPI. The original

\footnotetext{
${ }^{4}$ These norms are now replaced by substantially revised anthropometric norms prepared by WHO (2006).

${ }^{5}$ This is a summary of the material provided by Sonal Desai.
} 
HDPI was a random sample of 33,230 households, located in 16 major states, 195 districts and 1765 villages. In states where the 1993-94 survey was conducted and recontact details were available, 13593 households were randomly selected for reinterview in 2005. About 82 per cent of the households were contactable for reinterview resulting in a resurvey of 11,153 original households as well as 2,440 households which had separated from the original households but were still living in the same village.

In each district where reinterviews were conducted, two fresh villages were randomly selected using a probability proportional to size technique. In each village, 20 randomly selected households were selected. Additionally, 3,993 households were randomly selected from the states where the 1993-94 survey was not conducted, or where recontact information was not available.

In order to draw a random sample of urban households, all urban areas in a state were listed in the order of their size with number of blocks drawn from each urban area allocated based on probability proportional to size. After determining the number of blocks, the enumeration blocks were selected randomly. From these enumeration blocks (of about 150-200 households), a complete household listing was obtained and a sample of 15 households was selected per block.

The questions fielded in IHDS were organised into two questionnaires, household and women. The household questionnaires were administered to the individual most knowledgeable about income and expenditure, frequently the male household head; the questionnaire for health and education were administered to a woman in the householdtypically the female spouse of the household head.

Comparison of IHDS data with the National Sample Survey or NSS (2004-05), National Family Health Survey III (2005-06) and Census (2001) confirms the robustness of IHDS data. For example, IHDS sample distribution on urban residence, caste and religion is remarkably similar to NSS and NFHS-III, although all three surveys (IHDS, NSS and NFHS) have higher proportions of households claiming Scheduled Caste status than enumerated in Census (2001).

Two familiar problems with anthropometric data are noted. One is the large number of children in the sample without anthropometric measurements or those whose measurements 
are improbable (about 46 per cent). ${ }^{6}$ So the small sample may be biased but the nature and magnitude of the bias is uncertain. ${ }^{7}$

\section{Composite Index of Anthropometric Failure}

Generally, three indicators of anthropometric failure for children are used. These comprise being underweight (low weight for age), stunted (low height for age) and wasted (low weight for height). Specifically, when the weight for age falls below $-2 z$ score of the reference population median; a child is classified as underweight. In case it is below -3z score of the median, the child is classified as severely underweight. A child is stunted if the height for age is below $-2 \mathrm{z}$ score of the reference median, and severely stunted if below -3z score. Wasting refers to weight for height being below $-2 \mathrm{z}$ score of the reference median.

Each measure seeks to capture specific aspects of undernutrition. A child may be underweight because of chronic or acute deprivation of food and/or health care. Stunting, on the other hand, is a consequence of chronic deprivation of food and/or a prolonged or frequent illness. Wasting is an indicator of acute deprivation of food and/or illness. This is referred to as the standard Waterlow 3-tier scheme.

Svedberg (2000) emphasises that these measures are not independent identities, and the fact that weight for age indicator (W/A), is identically equal to the product of the other two, (H/A) $\mathrm{x}(\mathrm{W} / \mathrm{H})$, implies that it will miss some of the children who are undernourished in the two latter dimensions. The total prevalence of anthropometric failure in a population will thus be underestimated by the weight for age indicator (as also by any of the other too). If failure in each of the three indicators is of concern, that is, to be stunted, underweight, or wasted, has negative effects on a child's health and functions (of varying degrees), it follows that none of three conventional measures will capture all children who fail in at least one of these three dimensions. Thus an aggregate measure of anthropometric failure is necessary.

Towards this objective, Svedberg (2000) identifies 6 groups of undernourished children as shown in Table 1 . The sum of groups 2-7 constitutes a measure of total undernourished. Dividing this by the sum of groups 1-7 and multiplying by 100 gives the proportion of children undernourished.

\footnotetext{
${ }^{6}$ In a total sample of 24314 children in the age-group of 0-5 years, barely 13524 had anthropometric measurements.

${ }^{7}$ Whether these problems result in underestimation of undernutrition — as conjectured by Nandy et al. 2005 — seems plausible but subject to validation.
} 
Table 1

Classification of Undernourished Children (under 5 years)

\begin{tabular}{|c|l|c|c|c|}
\hline Group & Description & Wasting & Stunting & Underweight \\
\hline 1 & $\begin{array}{l}\text { No Failure: Children whose height and weight are } \\
\text { above the age-specific norms (i.e. above -2 z scores) and } \\
\text { do not suffer from any anthropometric failure }\end{array}$ & No & No \\
\hline 2 & $\begin{array}{l}\text { Wasting only: Children with acceptable weight and } \\
\text { height for their age but who have subnormal weight for } \\
\text { height }\end{array}$ & Yes & No & No \\
\hline 3 & $\begin{array}{l}\text { Wasting and underweight: children with above norm } \\
\text { heights but whose weight for age and weight for height } \\
\text { are too low. }\end{array}$ & Yes & Yes \\
\hline 4 & $\begin{array}{l}\text { Wasting, stunting and underweight: Children who } \\
\text { suffer from anthropometric failure on all three measures. }\end{array}$ & Yes & Yes & Yes \\
\hline 5 & $\begin{array}{l}\text { Stunting and underweight: Children with low weight } \\
\text { for age but who have acceptable weight, both for their } \\
\text { age and for their short height. }\end{array}$ & No & Yes \\
\hline 6 & $\begin{array}{l}\text { Stunting only: Children with low height for age but } \\
\text { who have acceptable weight, both for their age and for } \\
\text { their short height. }\end{array}$ & No & Yes & No \\
\hline 7 & Underweight only: Children who are only underweight. & No & No & Yes \\
\hline
\end{tabular}

Source: Based on Nandy et al. (2005). Note that the combination of wasted and stunted is not physically possible since a child cannot simultaneously experience stunting and wasting and not be underweight.

To further clarify the identification of these groups of undernourished, a Venn diagram is constructed in Figure $1 .^{8}$ As may be noted from it, A denotes underweight, B denotes stunted and $\mathrm{C}$ denotes wasted children. $\mathrm{AB}$ denotes children who are underweight and stunted, $\mathrm{AC}$ represents those who are underweight and wasted, and ABC denotes those who are underweight, stunted and wasted. B-AB, for example, gives the number of stunted only.

The results of an earlier analysis by Nandy et al. (2005), based on NFHS-2, are given in Table 2. ${ }^{9}$ The estimates of anthropometric failure were constructed for the age-group 0-3 years.

According to Nandy et al. (2005), 45 per cent of children were stunted, 47 per cent were underweight and 16 per cent were wasted. The CIAF was considerably higher (about 60 per cent) than any of these indicators.

\footnotetext{
${ }^{8}$ Diagrammatic illustrations of 6 categories of anthropometric failures and an extended one that allows for overweight as well are given in the annex. These are based on Svedberg (2007).

${ }^{9}$ The reference population is the NCHS.
} 


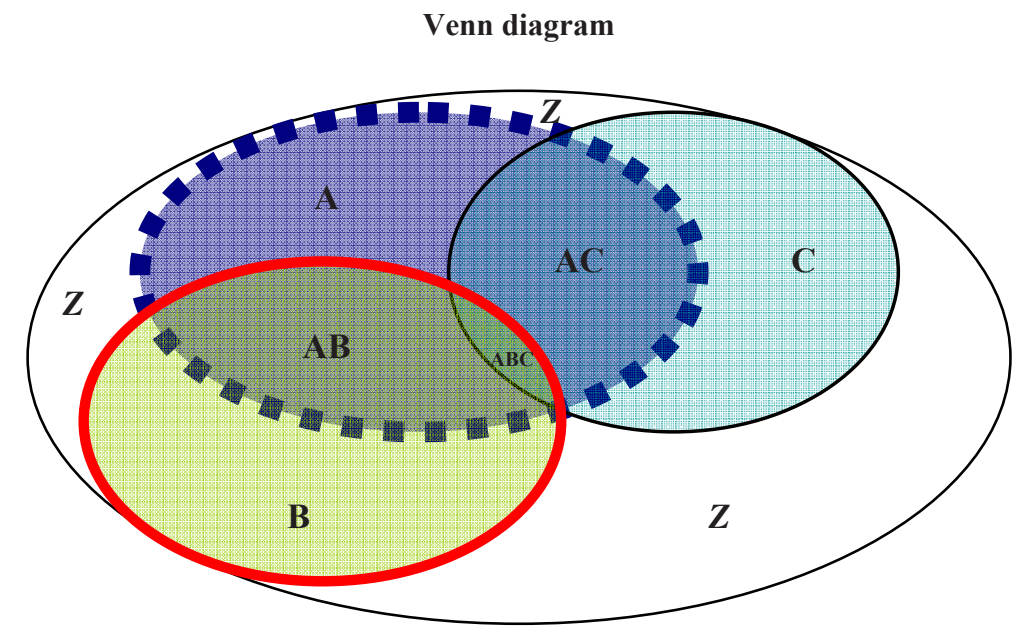

Z=No Anthropometric Failure, A=Underweight, B= Stunted, C=Wasted, $\mathrm{AB}=$ Underweight \& Stunted, AC= Underweight \& Wasted, $\mathrm{ABC}=$ Underweight, Stunted \& Wasted

Figure 1: Subgroups of Undernourished Children

Table 2

Prevalence of Undernutrition among Children 0-3 years old in India in 1998-99

\begin{tabular}{|c|c|}
\hline Group & \% Children \\
\hline Stunted & 45.2 \\
\hline Wasted & 15.9 \\
\hline Underweight & 47.1 \\
\hline CIAF & 59.8 \\
\hline
\end{tabular}

Source: Nandy et al. (2005)

Of the six subgroups of undernourished children, those stunted and underweight accounted for well over one- quarter of the children (Table 3), with all other subgroups accounting for substantially lower shares. Those simultaneously wasting, stunted and underweight accounted for about 7 per cent of the sample.

Their findings on negative health effects corroborate the usefulness of the disaggregated classification of undernourished children. A summary is given below. ${ }^{10}$

\footnotetext{
${ }^{10}$ These results were obtained from a binary logistic regression of diarrhoea, severe diarrhoea and ARI on anthropometric failures. It is not clear whether any allowance was made for the endogeneity of anthropometric failures.
} 
Those with multiple anthropometric failures (wasted and underweight, wasted, underweight and stunted, and stunted and underweight) were more likely to suffer from diarrhoea than those with only a single failure (wasted only, and stunted only). Those who were simultaneously wasted, stunted and underweight were in fact the most likely to suffer from diarrhoea.

Table 3

Subgroups of Anthropometric Failure among Children 0-3 Years Old in India in 1998-99

\begin{tabular}{|l|c|}
\hline Groups & \% Children \\
\hline 1. No Failure & 40.2 \\
\hline 2. Wasting Only & 2.6 \\
\hline 3. Wasting and Underweight & 6.1 \\
\hline 4. Wasting, Stunting and Underweight & 7.2 \\
\hline 5.Stunting and Underweight & 27.9 \\
\hline 6. Stunting only & 10.1 \\
\hline 7. Underweight only & 5.9 \\
\hline CIAF $(=2+3+4+5+6+7)$ or $=100-(1)$ & 59.8 \\
\hline
\end{tabular}

Source: Nandy et al. (2005)

Those with multiple anthropometric failures (wasted, stunted and underweight, and stunted and underweight) were far more likely to suffer from severe diarrhoea than those suffering from single failures (except the underweight).

Children with multiple failures (wasted and underweight, wasted, stunted and underweight, and stunted and underweight) were also more likely to suffer from acute respiratory infection (ARI).

Although analysis of risk of dying from these infectious diseases is rendered difficult by lack of anthropometric data on the dead and survivor bias, longitudinal data confirm that undernutrition (wasting and underweight) was twice as common among diseased children (Boerma et al. 1992). ${ }^{11}$

In sum, the disaggregation of undernourished children offers useful insights into risks of infectious diseases. These risks are aggravated for poor children given their limited access to health care.

${ }^{11}$ Boerma et al. (1992) and Svedberg (2000) also contain clear exposition of survivor bias. 


\section{Results Based on IHDS 2004-05}

Let us first consider some cross-tabulations of conventional indicators of anthropometric failure among 5-year old children. Note that these are obtained using the recent WHO (2006) norms.

\section{(a) Cross-Tabulations of Anthropometric Failures}

The prevalence rates of both children being underweight and stunted are high-especially the former. Wasting is relatively low but still afflicts about one-fifth of children under 5 years. What is also worrying is that nearly half of underweight and stunted children are severely so (Table 4).

Table 4

Groups of Anthropometric Failure in 2004-05

\begin{tabular}{|l|c|c|c|}
\hline Groups & $\begin{array}{c}\text { Moderate } \\
(<-3 z-2 z)\end{array}$ & $\begin{array}{c}\text { Severe } \\
(<-3 z)\end{array}$ & $\begin{array}{c}\text { Total } \\
\text { (including moderate } \\
\text { and severe failure) }\end{array}$ \\
\hline Underweight & 20.69 & 20.73 & 41.42 \\
\hline Stunted & 17.10 & 18.99 & 36.09 \\
\hline Wasting & 12.55 & 9.38 & 21.39 \\
\hline
\end{tabular}

We then examine whether there is a large overlap between poverty and child undernutrition. Specifically, the question is whether undernutrition is largely a manifestation of poverty. Using the official poverty line, we construct cross-tabulations of different measures of child undernutrition and poverty status. ${ }^{12}$

Table 5 gives a cross-tabulation of underweight children and poverty status of their households. The contrast between poor and non-poor households is striking. Prevalence of underweight is markedly higher among poor children than among the non-poor. Severely underweight children account for just under one-quarter of poor children as against under one-fifth of non-poor children.

Table 5

Underweight by Poverty Status in 2004-05

\begin{tabular}{|c|c|c|}
\hline Underweight & Poor & Non-Poor \\
\hline Severe & $24.09(37.89)$ & $19.00(62.11)$ \\
\hline Moderate & $22.76(35.91)$ & $19.62(64.09)$ \\
\hline Total & $46.85(36.89)$ & $38.62(63.11)$ \\
\hline
\end{tabular}

Note: Figures within brackets denote shares of total underweight children.

\footnotetext{
12 The average poverty line is Rs 356 per person per month in rural areas and rs 538 in urban areas (Desai, 2010).
} 
However, going by their shares in total underweight children, the non-poor underweight children accounted for just under 2/3rds of the total (Table 6).

Table 6

Stunting by Poverty Status in 2004-05

\begin{tabular}{|l|c|c|}
\hline Stunting & Poor & Non-Poor \\
\hline Severe & $21.62(37.53)$ & $17.51(62.47)$ \\
\hline Moderate & $18.64(35.42)$ & $16.54(64.58)$ \\
\hline Total & $40.26(36.52)$ & $34.05(63.48)$ \\
\hline
\end{tabular}

Note: Figures within brackets denote shares of total stunted children.

These findings imply that, while poor children are more likely to be underweight, the number of non-poor underweight children far exceeds that of the poor. Although income deprivation is closely related to the prevalence of underweight, other factors (e.g. home environment) seem more important.

As in the case of underweight, prevalence of stunting is much higher among poor children, as also of severe stunting.

However, the number of non-poor stunted children far exceeds that of poor children, as also that of severely stunted children.

The conclusion, therefore, is that factors associated with stunting are not confined to income deprivation - indeed, other factors (e.g. home environment, mother's education) seem to have a more important role.

Prevalence rates of wasting do not vary much between the poor and non-poor children. Also, prevalence of severe wasting is nearly equal.

However, the number of non-poor wasting children far exceeds that of the poor (Table 7).

Table 7

Wasting by Poverty Status in 2004-05

\begin{tabular}{|c|c|c|}
\hline Wasting & Poor & Non-Poor \\
\hline Severe & $9.53(33.63)$ & $9.26(66.37)$ \\
\hline Moderate & $12.81(33.88)$ & $12.31(66.12)$ \\
\hline Total & $22.34(33.77)$ & $21.57(66.23)$ \\
\hline
\end{tabular}

Note: Figures within brackets denote shares of total wasting children. 
These results also point to factors that go beyond income deprivation. As income is often an unsatisfactory measure of economic well-being, caste is generally considered a useful proxy. Among the most deprived are the STs, followed by the SCs and then OBCs (Desai et al. 2010).

Table 8 shows that the prevalence of underweight is highest among STs, followed by SCs and then OBCs. However, OBCs account for the largest share of underweight children, followed by Others and then SCs.

Table 8

Underweight by Caste in 2004-05

\begin{tabular}{|c|c|c|c|}
\hline Caste & Severe & Moderate & Total \\
\hline SCs & $21.82(24.21)$ & $22.21(24.62)$ & $44.03(24.42)$ \\
\hline STs & $26.46(10.60)$ & $24.62(9.86)$ & $52.88(10.24)$ \\
\hline OBCs & $20.98(37.12)$ & $19.78(34.98)$ & $40.76(36.03)$ \\
\hline Others & $17.90(28.07)$ & $19.49(30.54)$ & $37.39((29.29)$ \\
\hline Total & 20.63 & 20.64 & 41.27 \\
\hline
\end{tabular}

Note: Figures within brackets denote shares of different castes in respective underweight categories (severe, moderate and total)

These findings further corroborate that, while income matters, other factors not related to it matter more.

A similar pattern is revealed by Table 9. While STs and SCs have higher prevalence rates of stunting, OBCs and Others account for much larger shares of stunted children. These findings also point to not just income but other factors (e.g. home environment, food prices) not related to it — especially the latter-playing important roles in determining stunting.

Table 9

Stunting by Caste in 2004-05

\begin{tabular}{|c|c|c|c|}
\hline Caste & Severe & Moderate & Total \\
\hline SC & $20.60(25.56)$ & $17.69(24.02)$ & $38.29(24.80)$ \\
\hline ST & $21.65(9.60)$ & $17.90(8.69)$ & $39.55(9.15)$ \\
\hline OBC & $18.58(36.33)$ & $17.77(38.02)$ & $36.35(37.13)$ \\
\hline Others & $17.13(28.50)$ & $16.08(29.28)$ & $33.21(32.79)$ \\
\hline Total & 18.86 & 17.23 & 36.09 \\
\hline
\end{tabular}

Note: Figures within brackets denote shares of different castes in respective stunting categories (severe, moderate and total) 
Table 10 cross-classifies wasting by caste. The pattern is similar to those in Tables 8 and 9. While the most disadvantaged STs have the highest prevalence of stunting, SCs and OBCs have lower rates. OBCs and Others, on the other hand, account for the largest shares, followed by SCs. So the inference about the greater importance of factors unrelated to income in determining wasting is implied.

Table 10

Wasting by Caste

\begin{tabular}{|c|c|c|c|}
\hline Caste & Severe & Moderate & Total \\
\hline SC & $9.64(24.29)$ & $11.66(22.0)$ & $21.3(22.93)$ \\
\hline ST & $13.79(12.29)$ & $14.93(9.96)$ & $28.72(10.96)$ \\
\hline OBC & $8.40(32.67)$ & $12.48(36.36)$ & $20.88(34.79)$ \\
\hline Others & $9.04(30.75)$ & $12.43(31.68)$ & $21.47(31.32)$ \\
\hline Total & 9.34 & 12.47 & 21.81 \\
\hline
\end{tabular}

Note: Figures within brackets denote shares of different castes in respective wasting categories (severe, moderate and total)

\section{(b) Construction of CIAF}

In Table 11, the CIAF and its subgroups are given. Table 11 points to more pervasive anthropometric failure in terms of the CIAF relative to conventional indicators of being underweight, stunted or wasted. The CIAF is about 59 per cent. Among the subcategories, stunting and underweight and stunting alone account for well over half of the CIAF. Children who fail in all three dimensions (simultaneously wasted, stunted and underweight) account for a non-negligible share (13.5 per cent). The underweight alone account for the lowest share (about 6 per cent).

Table 11

Subgroups of Child Undernutrition and CIAF in 2004-05

\begin{tabular}{|l|c|}
\hline Groups & Share of Under 5 Children (\%) \\
\hline 1. No Failure & 41.36 \\
\hline 2. Wasting Only & 6.86 \\
\hline 3. Wasting and Underweight & 9.41 \\
\hline 4. Wasting, Stunting and Underweight & 7.92 \\
\hline 5. Stunting and Underweight & 19.80 \\
\hline 6. Stunting Only & 11.08 \\
\hline 7. Underweight Only & 3.57 \\
\hline CIAF (=2+3+4+5+6+7) & 58.64 \\
\hline
\end{tabular}


The contrast between the poor and non-poor children is striking. The CIAF is considerably higher among poor children than among the non-poor. However, the number of poor children suffering from any of the anthropometric failures is considerably lower than that of non-poor.

Among poor children, the proportion of both stunted and underweight children was highest, followed by that of stunted alone, and then wasted and underweight, and simultaneously wasted, stunted and underweight. If we go by the shares of subgroups of poor undernourished children in total of each, stunted and underweight children account for just under 39 per cent of the total, followed by the wasted, stunted and underweight (under 38 per cent). These imply that numbers of each from the non-poor far exceed those from the poor (Table 12).

Table 12

Subgroups of Child Undernutrition and CIAF by Poverty Status in 2004-05

\begin{tabular}{|l|c|c|}
\hline \multirow{2}{*}{ Groups } & \multicolumn{2}{|c|}{ Share of Under 5 Children (\%) } \\
\cline { 2 - 3 } & Poor & Non-Poor \\
\hline 1.No Failure & $36.46(28.82)$ & $43.74(71.18)$ \\
\hline 2.Wasting Only & $6.26(29.84)$ & $7.15(70.16)$ \\
\hline 3.Wasting and Underweight & $9.80(34.05)$ & $9.22(65.95)$ \\
\hline 4.Wasting, Stunting and Underweight & $9.11(37.62)$ & $7.34(62.38)$ \\
\hline 5.Stunting and Underweight & $23.57(38.92)$ & $17.97(61.08)$ \\
\hline 6.Stunting Only & $11.04(32.54)$ & $11.11(67.46)$ \\
\hline 7.Underweight Only & $3.76(34.44)$ & $3.48(65.56)$ \\
\hline CIAF (=2+3+4+5+6+7) & $63.54(35.42)$ & $56.26(64.58)$ \\
\hline
\end{tabular}

Note: Figures within brackets are shares of total or each group.

As caste and economic well-being are closely correlated, Table 13 contains a crossclassification of subgroups of undernourished children by caste. The main findings are given below.

The CIAF is highest among ST children, followed by SCs and OBCs. However, OBCs account for the largest share, followed by Others and then SCs. Prevalence rate of stunting and being underweight are highest among SCs, followed by STs and then OBCs. However, OBCs account for the largest share of stunted and underweight children, followed by Others and then SCs. Prevalence of stunting alone was highest among STs, followed by Others and 
then OBCs but within a narrow range. However, OBCs accounted for well over one-third of the total (about 37.50 per cent), followed by Others (over 32 per cent) and then SCs (under 22 per cent). Prevalence of wasting and underweight was highest among STs (about 15.50 per cent), followed by SCs and then Others-all within a narrow range. However, OBCs accounted for the largest share (over one-third), followed by Others (under 30 per cent). The triple failure of stunting, wasting and underweight is highest among ST children, followed by OBCs and then SCs. OBCs, however, account for the largest share (about 37.50 per cent), followed by Others (over 27 per cent) and then SCs (under 24 per cent).

Table 13

Subgroups of Child Undernutrition and CIAF by Caste in 2004-05

\begin{tabular}{|c|c|c|c|c|c|}
\hline \multirow{2}{*}{ Groups } & \multicolumn{5}{|c|}{ Shares of Under 5 Children (\%) } \\
\hline & SCs & STs & OBCs & Others & Total \\
\hline 1. No Failure & $\begin{array}{c}39.57 \\
(22.43) \\
\end{array}$ & $\begin{array}{l}31.42 \\
(6.28) \\
\end{array}$ & $\begin{array}{c}42.37 \\
(37.79) \\
\end{array}$ & $\begin{array}{c}44.12 \\
(33.50) \\
\end{array}$ & $\begin{array}{r}41.36 \\
(100) \\
\end{array}$ \\
\hline 2. Wasting Only & $\begin{array}{c}6.08 \\
(20.76) \\
\end{array}$ & $\begin{array}{c}6.33 \\
(7.63) \\
\end{array}$ & $\begin{array}{c}6.47 \\
(34.78) \\
\end{array}$ & $\begin{array}{c}8.03 \\
(36.82) \\
\end{array}$ & $\begin{array}{r}6.86 \\
(100)\end{array}$ \\
\hline 3. Wasting and Underweight & $\begin{array}{c}9.30 \\
(23.17)\end{array}$ & $\begin{array}{c}15.46 \\
(13.59)\end{array}$ & $\begin{array}{c}8.66 \\
(33.96)\end{array}$ & $\begin{array}{c}8.77 \\
(29.28)\end{array}$ & $\begin{array}{l}9.41 \\
(100)\end{array}$ \\
\hline $\begin{array}{l}\text { 4. Wasting, Stunting and } \\
\text { Underweight }\end{array}$ & $\begin{array}{c}7.98 \\
(23.62)\end{array}$ & $\begin{array}{c}11.29 \\
(11.80)\end{array}$ & $\begin{array}{c}8.03 \\
(37.41)\end{array}$ & $\begin{array}{c}6.85 \\
(27.16)\end{array}$ & $\begin{array}{l}7.92 \\
(100) \\
\end{array}$ \\
\hline 5. Stunting and Underweight & $\begin{array}{c}22.96 \\
(27.18) \\
\end{array}$ & $\begin{array}{l}20.46 \\
(8.55) \\
\end{array}$ & $\begin{array}{c}19.63 \\
(36.57) \\
\end{array}$ & $\begin{array}{c}17.47 \\
(27.70) \\
\end{array}$ & $\begin{array}{l}19.80 \\
(100) \\
\end{array}$ \\
\hline 6. Stunting Only & $\begin{array}{c}10.26 \\
(21.70) \\
\end{array}$ & $\begin{array}{l}11.44 \\
(8.53) \\
\end{array}$ & $\begin{array}{c}11.26 \\
(37.48)\end{array}$ & $\begin{array}{c}11.40 \\
(32.28)\end{array}$ & $\begin{array}{l}11.08 \\
(100)\end{array}$ \\
\hline 7. Underweight Only & $\begin{array}{c}3.85 \\
(25.23) \\
\end{array}$ & $\begin{array}{l}3.60 \\
(8.34) \\
\end{array}$ & $\begin{array}{c}3.58 \\
(36.93) \\
\end{array}$ & $\begin{array}{c}3.36 \\
(29.50) \\
\end{array}$ & $\begin{array}{l}3.57 \\
(100) \\
\end{array}$ \\
\hline CIAF $(=2+3+4+5+6+7)$ & $\begin{array}{c}60.43 \\
(24.15)\end{array}$ & $\begin{array}{l}68.58 \\
(9.67) \\
\end{array}$ & $\begin{array}{c}57.63 \\
(36.25)\end{array}$ & $\begin{array}{c}55.88 \\
(29.92)\end{array}$ & $\begin{array}{l}58.64 \\
(100)\end{array}$ \\
\hline
\end{tabular}

Note: Figures within brackets are shares of total or each group.

We now turn to anthropometric failure by location. The cross-tabulation of anthropometric failure by location (rural, metro and non-metro urban areas) is given in Table 14.

The CIAF is highest in rural areas-over 60 per cent of under 5 children are afflicted in one way or another, followed by metro (over 54 per cent) and Non-metro urban (under 53 per cent). These estimates imply that anthropometric failure affects not just rural areas but also urban areas. However, more than three-fourths of the children suffering from diverse 
anthropometric failures lived in rural areas, and relatively small shares in non-metro urban (about 16.50 per cent) and metros (just under 6 per cent).

Table 14

Subgroups of Child Undernutrition and CIAF by Location in 2004-05

\begin{tabular}{|l|c|c|c|c|}
\hline \multirow{2}{*}{ Groups } & \multicolumn{4}{|c|}{ Share of Under 5 Children (\%) } \\
\cline { 2 - 5 } & Rural & $\begin{array}{c}\text { Metro } \\
\text { Urban }\end{array}$ & $\begin{array}{c}\text { Non-Metro } \\
\text { Urban }\end{array}$ & Total \\
\hline 1.No Failure & $39.61(72.37)$ & $45.67(6.86)$ & $47.13(20.76)$ & $41.36(100)$ \\
\hline 2.Wasting Only & $6.32(69.63)$ & $9.38(8.50)$ & $8.24(21.88)$ & $6.86(100)$ \\
\hline 3.Wasting and Underweight & $9.58(76.92)$ & $9.25(6.11)$ & $8.75(16.96)$ & $9.41(100)$ \\
\hline 4.Wasting, Stunting and Underweight & $8.60(82.14)$ & $6.18(4.85)$ & $5.65(13.01)$ & $7.92(100)$ \\
\hline 5.Stunting and Underweight & $21.16(80.74)$ & $14.36(4.51)$ & $16.03(14.75)$ & $19.80(100)$ \\
\hline 6.Stunting Only & $10.94(74.55)$ & $12.60(7.06)$ & $11.18(18.39)$ & $11.08(100)$ \\
\hline 7.Underweight Only & $3.79(80.14)$ & $2.56(4.45)$ & $3.02(15.41)$ & $3.57(100)$ \\
\hline CIAF (=2+3+4+5+6+7) & $60.39(77.81)$ & $54.33(5.76)$ & $52.87(16.43)$ & $58.64(100)$ \\
\hline
\end{tabular}

Note: Figures within brackets are shares of total or each group.

Turning to the subcategories, the most pervasive or prevalent is stunting and underweight. A little over fifth of the rural children were afflicted by these failures, followed by non-metro urban (under 15 per cent) and then metros (about 4.50 per cent). However, a vast majority of the total (under 81 per cent) were in rural areas.

Prevalence of stunting alone was highest in metros (under 13 per cent), followed closely by non-metro urban (over 11 per cent) and rural areas (just under 11 per cent). However, the majority of stunted children (74.50 per cent) were in rural areas.

Prevalence of wasting and underweight was slightly lower than that of stunting alone but non-negligible. Highest prevalence was in rural areas, followed by metro and then non-metro urban areas but all within a narrow range. The vast majority of wasted and underweight children, however, were rural.

The triple failure of stunting, wasting and underweight is under 9 per cent in rural areas, and slightly lower in metro (over 6 per cent) and then in non-metro urban areas (under 6 per cent). As in other cases, rural areas accounted for the largest share of the total (over 82 per cent). 
In sum, the CIAF and its disaggregation into subcategories of undernourished 5 years old children point reveal a grimmer story of child undernutrition than conventional anthropometric indicators do. Not only is the prevalence of undernutrition in its diverse forms higher but also simultaneous occurrence of anthropometric failures (e.g. stunting and underweight, and stunting, wasting and underweight) varies from moderate to high. Although poor children in general are more vulnerable to these failures, it is non-poor or (relatively) affluent children who account for significantly larger shares of total undernourished children. Locationally, rural children are not just most prone to failures in any of the anthropometric dimensions and their simultaneous occurrence but also account for the large majority of total undernourished children.

\section{(c) Stochastic Dominance Tests}

Cumulative distributions (CD) of anthropometric indicators are plotted against log per capita expenditure separately for rural areas, metros and non-metro urban areas. Consider the CD of wasting only in Fig A3. Over the entire range of (log of) per capita expenditure, the CD for metros stochastically dominates that for non-metro urban areas and the latter dominates that of rural areas. So in terms of the FGT class of indices of wasting, rural areas are the worstoff, followed by non-metro urban areas.

Fig A4 leads to a similar conclusion for wasting and underweight with the rural areas the worst-off, followed by non-metro urban areas.

Fig A5 contains the CDs for the triple anthropometric failures of wasting, stunting and underweight. Since the CD for rural areas lies above those for non-metro urban areas and metros, the rural areas are the most deprived in terms of this indicator, followed by non-metro urban areas.

Fig A6 tells an equally grim story of nutritional deprivation in terms of the double anthropometric failures of stunting and underweight with the rural areas as the worst-off.

Fig A7 illustrates a wide gap between the CDs of stunting only between the rural and nonmetro urban areas. This shows the large disparity in terms of chronic deprivation manifesting itself in stunting only. 
Fig A8 points to a mixed pattern of the CDs of underweight only. While the CD for rural areas is stochastically dominated by that for non-metro urban areas, the CD for metros crosses over that for non-metro urban areas at a low level of per capita expenditure (near the poverty cut-off point) and again at a slightly higher level of per capita expenditure. This pattern implies unambiguously that the rural areas are the worst-off in terms of underweight 5 year old children.

Comparison of CDs of CIAF on the basis of Fig A9 further corroborates the glaring gaps in child undernutrition between rural and non-metro urban areas on the one hand, and not-soglaring gaps between the latter and metros.

\section{Determinants of Anthropometric Failures}

As cross-tabulations do not simultaneously control for the effects of correlates other than those considered individually, we have carried out a regression analysis of the factors associated with the Composite Index of Anthropometric Failure (CIAF).

\section{(a) Specification of Model}

A regression model is specified, as given below, and estimated with household data. A general form of the regression model as it applies to all $\mathrm{n}$ observations is:

$\mathbf{y}=\mathbf{X \beta}+\varepsilon$

where $\mathbf{y}$ represents a column vector of all $\mathrm{n}$ observations on the dependent variable, the Composite Index of Anthropometric Failure or the CIAF, $\mathbf{X}$ is an $\mathrm{n} x \mathrm{~K}$ data matrix of $\mathrm{K}$ explanatory variables, and $\boldsymbol{\varepsilon}$ is a column vector of $\mathrm{n}$ disturbances.

First, the regression is estimated using OLS. After checking for heteroscedasticity, a robust regression that adjusts the standard errors accordingly is estimated.

\section{(b) Results}

As the Breusch-Pagan test statistic $\left(\chi_{1}^{2}=21.27\right)$ rejects homoscedasticity, our comments relate to robust regression results in Tables 15 and 16. 
Table 15

Regression Analysis of Factors Associated with CIAF: Robust Regression

\begin{tabular}{|c|c|c|}
\hline Explanatory variables & Coefficient (t-value) & Elasticity \\
\hline Age: Household Head & $-0.001 *(-1.66)$ & -0.071 \\
\hline SC & $0.018(0.79)$ & 0.006 \\
\hline ST & $0.013(0.36)$ & 0.002 \\
\hline OBC & $0.021(1.03)$ & 0.012 \\
\hline Gender: Household Head & $0.016(0.28)$ & 0.001 \\
\hline Marital Status: Household Head & $0.022(0.51)$ & 0.033 \\
\hline Years of Education: Household Head & $-0.005 * *(-2.01)$ & -0.041 \\
\hline Number of Children (0-5 years) & $-0.045^{* * *}(-3.34)$ & -0.099 \\
\hline Household Kitchen with Vent & $-0.062 * * *(-2.94)$ & -0.037 \\
\hline Piped water & $0.033(1.30)$ & 0.025 \\
\hline Hand pump or tube-well & $0.039(1.49)$ & 0.024 \\
\hline Rural areas & $0.049 *(1.85)$ & 0.053 \\
\hline Urban metros & $0.120 * * *(3.32)$ & 0.013 \\
\hline Log PCME (IV) & $-0.113 * * *(-3.50)$ & -0.184 \\
\hline Log Price: rice & $0.022(0.52)$ & 0.035 \\
\hline Log Price: wheat & $-0.121 * * *(-2.64)$ & -0.197 \\
\hline Log Price: sugar & $0.182 *(1.82)$ & 0.295 \\
\hline Log Price: kerosene & $-0.041(-0.86)$ & -0.067 \\
\hline Log Price: other-cereals & $-0.019(-0.91)$ & -0.032 \\
\hline Log Price: cereal-product & $0.047(1.35)$ & 0.076 \\
\hline Log Price: pulses & $-0.129 * * *(-3.23)$ & -0.210 \\
\hline Log Price: meat & $-0.001(-0.05)$ & -0.002 \\
\hline Log Price: gur & $-0.037(-1.47)$ & -0.060 \\
\hline Log Price: edible oil & $-0.078(-0.82)$ & -0.127 \\
\hline Log Price: eggs & $0.075 *(1.70)$ & 0.122 \\
\hline Log Price: milk & $0.054(0.93)$ & 0.088 \\
\hline Log Price: milk-product & $-0.009(-0.71)$ & -0.015 \\
\hline Log Price: vegetables & $0.045(1.50)$ & 0.073 \\
\hline Log Price: salt-spices & $-0.056(-0.79)$ & -0.091 \\
\hline Log Price: tea-coffee-processed & $-0.015(-0.35)$ & -0.024 \\
\hline Log Price: paan-tobacco & $0.013(1.56)$ & 0.021 \\
\hline Log Price: fruits-nuts & $0.011(0.25)$ & 0.018 \\
\hline Constant & 1.670 & \\
\hline Number of observations & 4603 & \\
\hline $\mathrm{F}(32,4570)$ & $7.34 * * *$ & \\
\hline
\end{tabular}

Note: $* * *, * *, *$ and refer to significance at the $1 \%, 5 \%, 10 \%$ levels, respectively; $\mathrm{w}$ denotes weak significance at $>10 \%$ level. All prices are at the PSU level. 
Table 16

Anthropometric Failure and Infectious Diseases

\begin{tabular}{|c|c|c|c|c|c|c|}
\hline \multirow{3}{*}{$\begin{array}{l}\text { Anthropometric Group } \\
\text { 1. No Failure }\end{array}$} & \multirow{2}{*}{\multicolumn{2}{|c|}{\begin{tabular}{l}
\multicolumn{2}{c}{ Diarrhoea } \\
$\%$ Share Ratio
\end{tabular}}} & \multirow[t]{3}{*}{ t-value } & \multicolumn{2}{|c|}{$\begin{array}{l}\text { Acute Respiratory } \\
\text { Infection (ARI) }\end{array}$} & \multirow[t]{3}{*}{ t-value } \\
\hline & & & & $\%$ Shar & Ratio & \\
\hline & 26.61 & 1.0 & & 47.49 & 1.0 & \\
\hline 2. Wasting Only & 29.57 & 1.11 & -0.99 & 45.29 & 0.95 & 0.54 \\
\hline 3. Wasting and Underweight & 25.53 & 0.95 & 0.43 & 50.37 & 1.06 & -0.86 \\
\hline $\begin{array}{l}\text { 4. Wasting, Stunting and } \\
\text { Underweight }\end{array}$ & 31.96 & 1.20 & $-1.95^{*}$ & 44.74 & 0.94 & 0.77 \\
\hline 5. Stunting and Underweight & 32.82 & 1.23 & $-3.34^{* *}$ & 53.97 & 1.14 & $-2.75^{* *}$ \\
\hline 6. Stunting Only & 26.56 & 0.99 & 0.02 & 47.74 & 1.01 & -0.08 \\
\hline 7. Underweight Only & 30.67 & 1.15 & -1.11 & 46.83 & 0.99 & 0.14 \\
\hline
\end{tabular}

1. Ratio represents proportions suffering from a disease in an undernourished group divided by the proportion of no failure. Accordingly, the t-test is a comparison of the differences in mean proportions in each undernourished group and no failure group. The difference in means is proportion suffering from a disease in no failure group-proportion suffering from the same disease in an undernourished group.

* Denotes significance at the $5 \%$ level; ** denote significance at the $1 \%$ level.

Let us first consider the regression coefficients.

Age of household head and the composite index are negatively related. That is, the higher the age, the lower was the index. Caste and this index were unrelated. Nor were the gender of household head and the composite index related. The marital status of the household head (the spouses living together) also does not have any effect.

However, the schooling years of the household head (as also a proxy for mother's education) had a significant negative effect on the composite index of undernutrition of the children. This implies that the higher the educational attainment, the lower was the aggregate nutritional deprivation.

Somewhat surprisingly, the larger the number of 5 years old children the lower was the composite failure. We expected that the larger the number of children, the greater will be the competition for scarce food and medical care. Since the coefficient in question is negative, it implies the more significanr effect of economies of scale in food expenditure.

General hygiene in the kitchen -the presence of a vent- was negatively related to aggregate nutritional deprivation. Somewhat surprisingly, access to piped water, and hand pump and tubewell water had no effect. Whether this effect is dampened by the fact that most households in urban areas have access to piped water needs further investigation. As 
expected, both rural areas and metros had higher aggregate nutritional failures compared with non-metro urban areas. ${ }^{13}$

The higher the (instrumented) log of per capita expenditure, the lower was the composite nutritional failure.

There are significant price effects. As demonstrated in Gaiha et al. (2010), prices induce substitutions between different food commodities (including between different grades of, say, rice, vegetables) and thus in nutrient intakes. Given the reduced form, we cannot identify the effects on nutrient intakes. So our comments are confined to just which price effects are significant. Note that these prices are in logs and were constructed at the PSU level (villages in rural areas). Among cereals, the price of wheat has a significant negative effect on the composite index; the sugar price has a positive effect; the pulses’ price has a negative effect; the price of eggs has a positive effect; and the price of vegetables has a (weakly) significant positive effect. Somewhat surprising is the absence of a positive effect of the price of milk.

As statistically significant effects of variables may not be large, we comment briefly on the absolute magnitudes of their elasticities. The elasticities (absolute) of CIAF with respect to quality of the kitchen, schooling years of household head, age of household head and number of 5 years old children in the household are small. All of them have a negative sign. Location effects are positive and large, with that of rural areas considerably larger (more than four times) than that of metros (both relative to non-metro urban areas), ${ }^{14}$ income matters a great deal with higher incomes reducing considerably the prevalence rate of aggregate nutritional deprivation. In a somewhat striking contrast, the elasticities of CPIAF with respect to prices of food commodities are in some cases large. For instance, the elasticity (absolute) is highest for sugar, followed by pulses, wheat and then eggs. The price of vegetables, by contrast, has a (relatively) small effect.

Similar results are obtained when household head's education is replaced by highest education of adult males and females. As shown in Table 16, only the education of adult female has a significant negative effect on the CIAF. The elasticity, however, is lower than expected. But the negative effect is consistent with a widely reported result that maternal

\footnotetext{
${ }^{13}$ This may seem inconsistent with the stochastic dominance test results discussed earlier but it is not, as that analysis did not control for all the effects that the regression analysis does.

${ }^{14}$ In the STATA procedure, the elasticities are computed on the assumption of the same mean value of the Composite Index and differing means of the rural and metro households. The considerably larger fraction of rural households thus more than compensates for the lower marginal effect of the rural dummy.
} 
education level is associated with lower child undernutrition. A familiar explanation is that better educated mothers ensure better medical care and healthier diets for their children.

In sum, household characteristics-specifically, mother's education, quality of kitchen, number of 5 years old children, poverty, and location (whether in a rural area or in a metro) are closely linked to aggregate anthropometric failure. No less important are the effects of food prices. Although their influence through changes in nutrient intakes could not be identified, their reduced-form effects are strong in some cases. Thus there is a case for income growth together with food price stabilisation in curbing child undernutrition

\section{Infectious Diseases and Anthropometric Failure}

Svedberg $(2000,2007)$ and Nandy et al. (2005) have sought to validate the disaggregated classification of undernutrition of children by linking it to susceptibility to infectious diseases such as diarrhoea, severe diarrhoea and acute respiratory infection (ARI). A result of particular significance is that children suffering from more than one anthropometric failure are more susceptible to these diseases than those suffering from no failure or just one failure (with a few exceptions). Our analysis with the IHDS also focuses on these links but the results are mixed, as shown below.

Except for wasted and underweight, and stunted only, in all other groups the prevalence of diarrhoea was higher than in the reference group of no failure. The highest prevalence rate was among those children who were simultaneously stunted and underweight, and those who were wasted, underweight and stunted. That these differences are statistically significant is confirmed by the t-test.

The differences in the prevalence of ARI are less striking. The highest prevalence occurs among stunted and underweight, followed by wasted and underweight children. Somewhat surprisingly, children with the triple failure of wasting, stunting and underweight had a lower prevalence rate than that of no failure. However, only the difference between stunted and underweight and no failure children was statistically significant (Table 17).

In brief, there is support for the disaggregated classification of undernourished children for understanding better the prevalence of infectious diseases. Specifically, those with more than one failure were worse-off in this respect than children with no failure. 
Table 17

Anthropometric Failure and Infectious Diseases

\begin{tabular}{|c|c|c|c|c|c|c|}
\hline \multirow{3}{*}{ Anthropometric Group } & \multicolumn{2}{|c|}{ Diarrhoea } & \multirow{4}{*}{ t-value } & \multirow{2}{*}{\multicolumn{2}{|c|}{$\begin{array}{c}\text { Acute Respiratory } \\
\text { Infection (ARI) }\end{array}$}} & \multirow{3}{*}{ t-value } \\
\hline & \multirow{2}{*}{\multicolumn{2}{|c|}{$\begin{array}{l}\% \\
\text { Ratio }\end{array}$}} & & & & \\
\hline & & & & $\% \mathrm{Sh}$ & Ratio & \\
\hline 1.No Failure & 26.61 & 1.0 & & 47.49 & 1.0 & \\
\hline 2.Wasting Only & 29.57 & 1.11 & -0.99 & 45.29 & 0.95 & 0.54 \\
\hline 3.Wasting and Underweight & 25.53 & 0.95 & 0.43 & 50.37 & 1.06 & -0.86 \\
\hline 4.Wasting, Stunting and Underweight & 31.96 & 1.20 & $-1.95^{*}$ & 44.74 & 0.94 & 0.77 \\
\hline 5.Stunting and Underweight & 32.82 & 1.23 & $-3.34^{* *}$ & 53.97 & 1.14 & $-2.75^{* *}$ \\
\hline 6.Stunting Only & 26.56 & 0.99 & 0.02 & 47.74 & 1.01 & -0.08 \\
\hline 7.Underweight Only & 30.67 & 1.15 & -1.11 & 46.83 & 0.99 & 0.14 \\
\hline
\end{tabular}

Notes: Ratio represents proportions suffering from a disease in an undernourished group divided by the proportion of no failure. Accordingly, the t-test is a comparison of the differences in mean proportions in each undernourished group and no failure group. The difference in means is proportion suffering from a disease in no failure group-proportion suffering from the same disease in an undernourished group.

* Denotes significance at the $5 \%$ level; ** denote significance at the $1 \%$ level.

\section{Concluding Observations}

Some observations are made from a broad policy perspective.

A puzzling feature of the Indian economy is that a wide range of indicators including income/expenditure, health and education reflect a diverse pattern during the last decade and a half. In fact, while most welfare indicators have continued to improve, social progress has followed diverse patterns, ranging from accelerated progress in some fields to slowdown and even regression in others. Against this background, our analysis focused on the prevalence of undernutrition among children under 5 years old.

Following the recent literature, we constructed a composite indicator of anthropometric failure (CIAF) that refines the Waterlow-3 tier classification, using a nation-wide household survey.

The CIAF and its disaggregation into subcategories of undernourished 5 years old children reveal a grimmer story of child undernutrition than conventional anthropometric indicators do. Besides, simultaneous occurrence of anthropometric failures (e.g. stunting and underweight, and stunting, wasting and underweight) is pervasive.

Our analysis of determinants of CIAF yields some new insights. Briefly, household characteristics-specifically, a (proxy for) mother's education, quality of kitchen, number of 5 
years old children, poverty, and location (whether in a rural area or in a metro)-are all closely linked to aggregate anthropometric failure. No less important are the effects of food prices. Although their influence through changes in nutrient intakes could not be identified, their impacts are strong in some cases.

Investigation of the links between different anthropometric failures and prevalence of infectious diseases (viz. diarrhoea and acute respiratory infection) offers some justification for the disaggregated classification of undernourished children used here. Specifically, those with more than one failure were worse-off in this respect than children with no failure.

There is a strong case for income growth together with food price stabilisation in curbing child undernutrition. Education has the desired effect but it is less strong than expected. Improvement in the quality of home environment makes a difference too but it is not conditional on income or wealth alone. Awareness of the importance of household hygiene and sanitation needs inculcation-especially in rural areas.

As current experience with food price stabilisation is far from reassuring, careful attention must be given to expanding and strengthening supplementary child feeding programmes (e.g. Integrated Child Development Services or ICDS). As these programmes have been castigated for rampant corruption, diversion of resources and abysmal quality of food supplements, nothing short of a drastic overhaul will make a difference. Besides, while female literacy grows, awareness building for hygienic living among women could be inculcated through a revamped ICDS.

Although poverty is not the only correlate of child undernutrition, it is an important one. With sluggish agricultural growth, and unimpressive non-farm growth, interventions such as National Rural employment Guarantee Scheme (NREG) hold considerable promise of livelihood expansion in the rural areas. Our analysis suggests weak targeting of the poorest largely as a result of (relatively) high NREG wage rate undermining the self-selection mechanism. As corruption is rife, fractions of wages earned accrue to the participants. So both design and implementation failures of NREG require careful scrutiny remedial action.

In conclusion, a wide range of interventions that comprise not just income growth acceleration and food price stabilisation but also awareness building for hygienic living are necessary to curb child undernutrition. 


\section{References}

Behrman, J. and Deolalikar, A. (1988) 'Health and Nutrition', in H. Chenery and T.N. Srinivasan (eds) Handbook of Development Economics, Volume 1, Amsterdam: Elsevier Science Publishers, B.V.

Boerma, J., A.E. Sommerfelt and G.T. Bicego (1992) 'Child Anthropometry in Crosssectional Surveys in Developing Countries: An Assessment of the Survivor Bias', American Journal of Epidemiology, vol. 135.

Deaton, A. and J. Dreze (2009) 'Food and Nutrition in India: Facts and Interpretations', Economic and Political Weekly, XLIV(7).

Desai, S., A. Dubey, B. L. Joshi, M. Sen, A. Shariff and R. Vanneman (2010) Human Development in India: Challenge for a Society in Development, New Delhi: Oxford University Press.

Gaiha, R., R. Jha and Vani S. Kulkarni (2010) 'Obesity, Affluence and Urbanisation in India', ASARC Working Paper 2010/10, Canberra: ANU.

Nandy, S., M. Irving, D. Gordon, S.V. Subramanian and G.D. Smith (2005) 'Poverty, Child Undernutrition and Morbidity: New Evidence', Bulletin of the World Health Organisation, 83(3).

Sahn, D. and D.C. Stifel (2002) 'Robust Comparisons of Malnutrition in Developing Countries', American Journal of Agricultural Economics, 84(3).

Sen, Amartya (1985) Commodities and Capabilities, Amsterdam: North Holland.

Sen, Amartya (1999) Development as Freedom, New York: Knopf.

Svedberg, P. (2000) Poverty and Undernutrition: Theory, Measurement, and Policy, Oxford: Oxford University Press.

Svedberg, P. (2007) 'Taking Action for the World's Poor and Hungry People', Speaker Summary Note, Beijing, China, October 17-19 (mimeo).

World Health Organisation (2006) WHO Child Growth Standards: Length/Height for Age, Weight for Age, Weight for Length, Weight for Height and Body Mass Index for Age-Methods and Development Geneva. 


\section{Annex}

As noted in the main text, Svedberg (2000) distinguished six subgroups of undernourished children. Adding them up yields a composite index of anthropometric failures. Following the contribution of Nandy et al. (2005), a separate category of underweight alone was inserted in this classification. As the IHDS also confirms the presence of children who are underweight without being stunted or wasted, a Venn diagram was constructed to illustrate graphically all seven subgroups. Here we have reproduced two diagrams from Svedberg (2007) that illustrate his original classification of the CIAF and an expanded version including the overweight. As these diagrams are

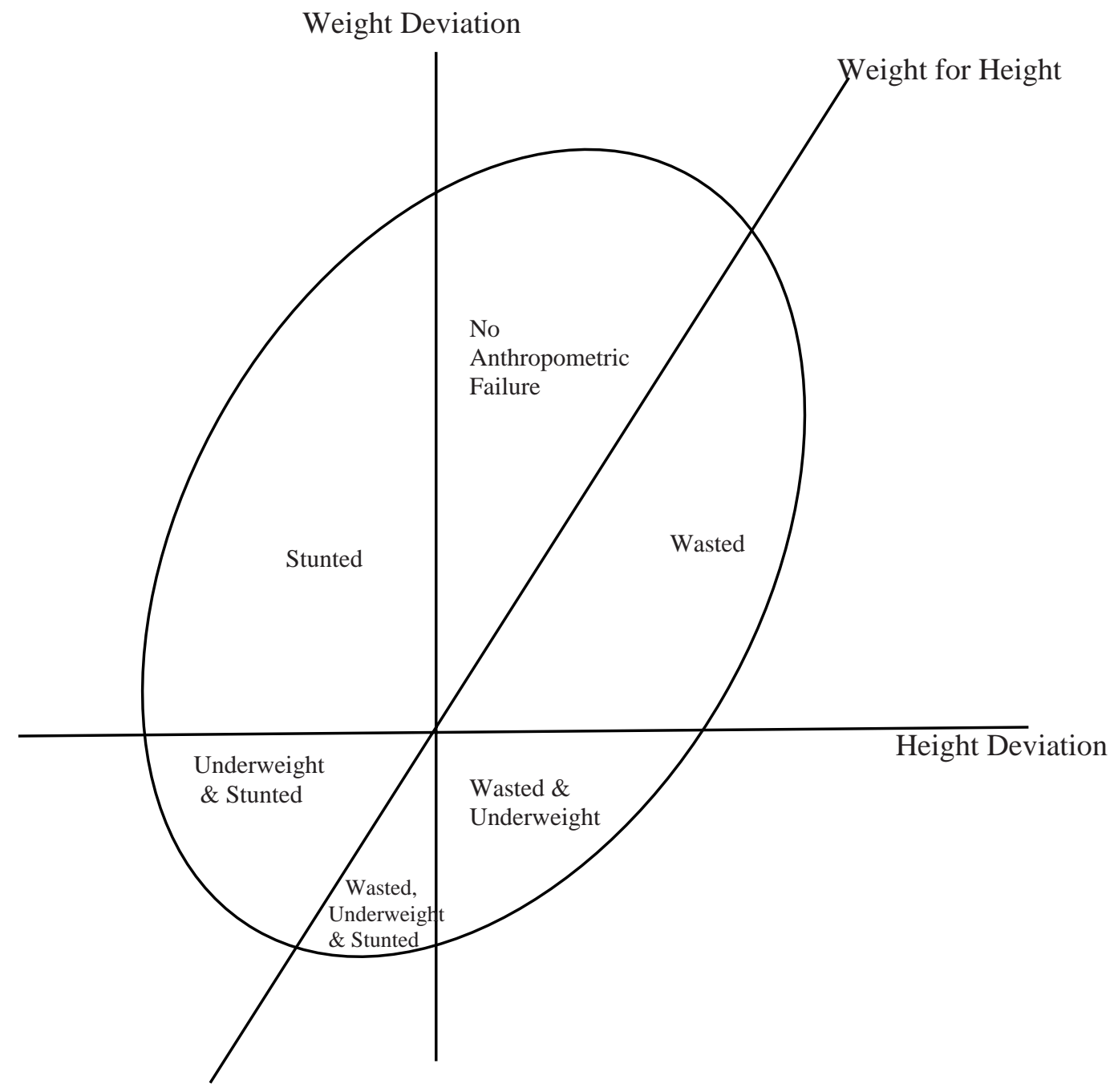

Source: Svedberg (2000)

Figure A1: Sub-Categories of Child Undernutrition 


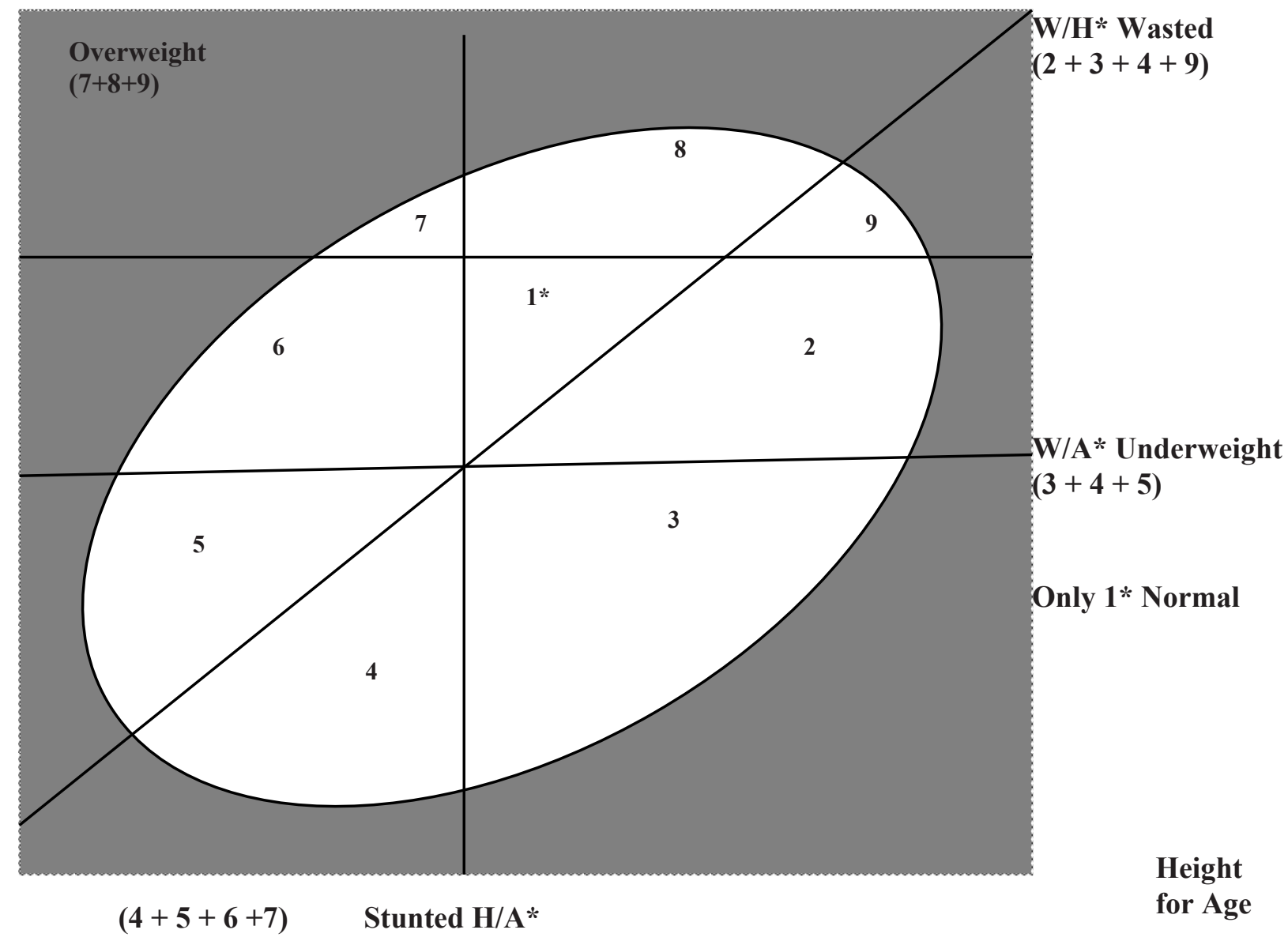

Where 1: No failure, 2: Wasted, 3: Underweight and Wasted, 4: Stunted, Wasted, and Underweight, 5: Stunted and Underweight, 6: Stunted only, 7: Overweight and Stunted, 8: Overweight only, 9: Overweight and Wasted

Source: Svedberg (2007)

Figure A2: CIAF-2 
Cumulative distribution of anthropometric indicators against log per capita expenditure

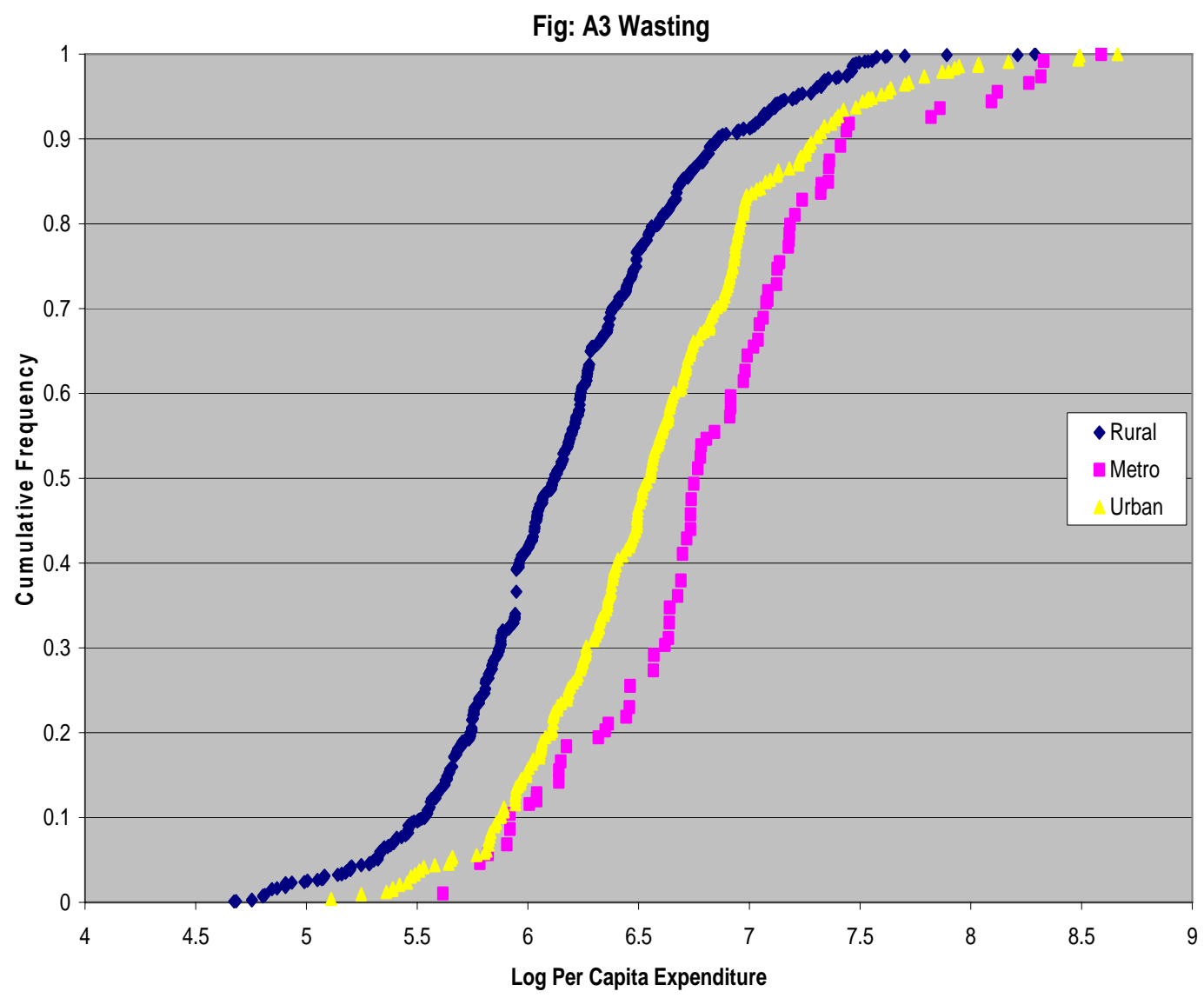

Figure A3: Cumulative distribution of wasting only against log per capita expenditure in rural, metro and urban India 
Cumulative distribution of anthropometric indicators against log per capita expenditure

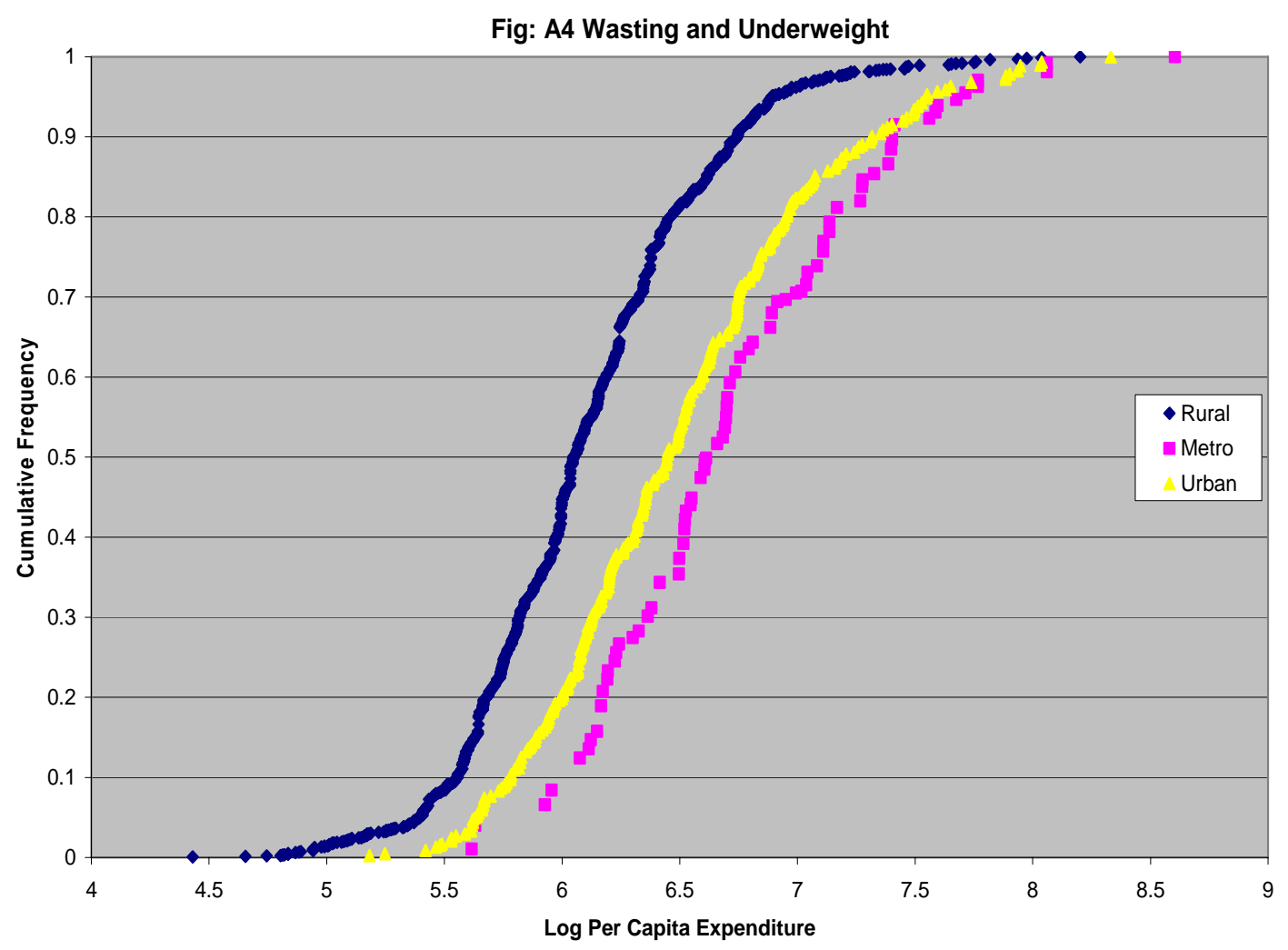

Figure A4: Cumulative distribution of wasting and underweight against log per capita expenditure in rural, metro and urban India 
Cumulative distribution of anthropometric indicators against log per capita expenditure

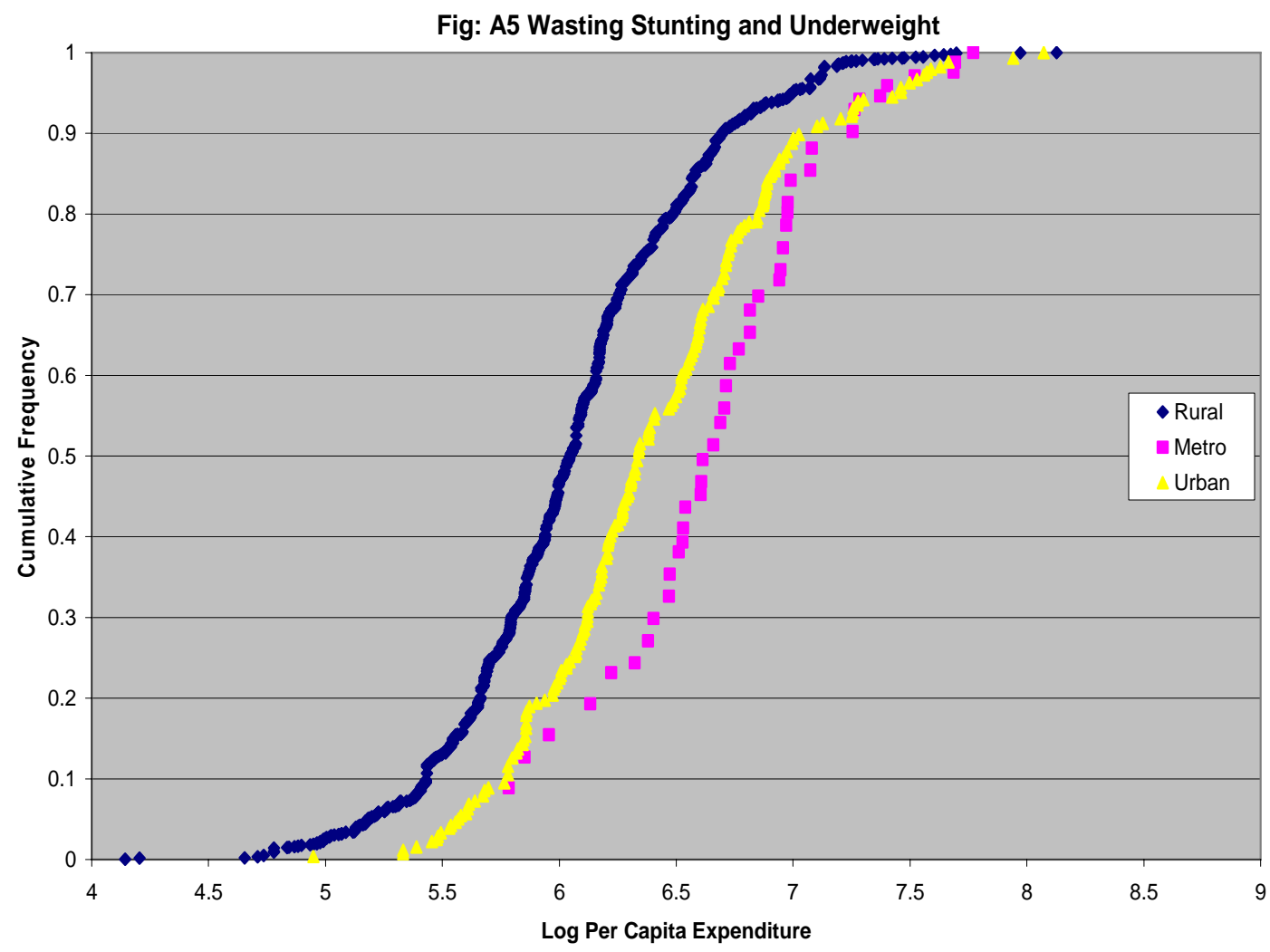

Figure A5: Cumulative distribution of wasting, stunting and underweight against log per capita expenditure in rural, metro and urban India 
Cumulative distribution of anthropometric indicators against log per capita expenditure

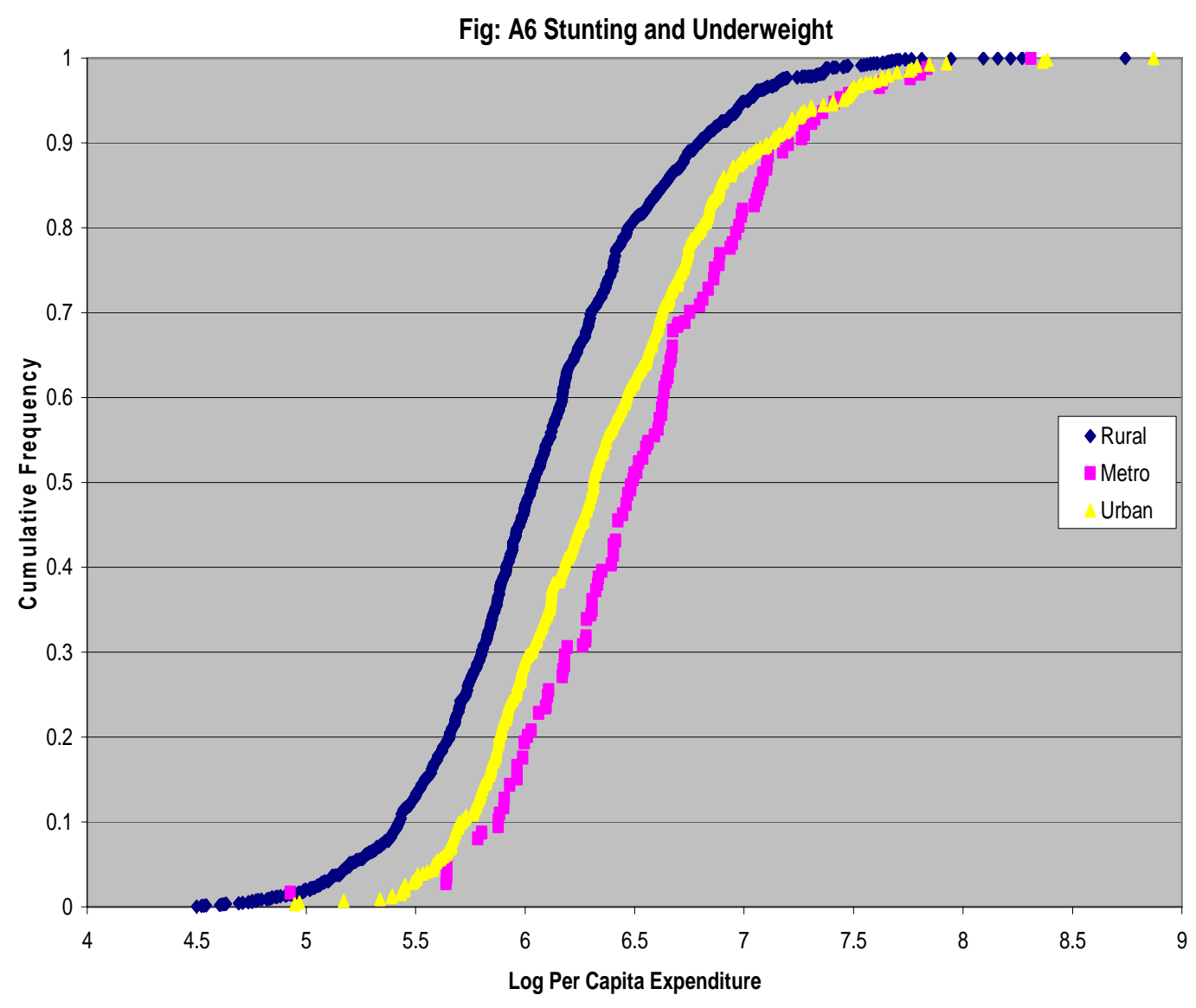

Figure A6: Cumulative distribution of stunting and underweight against log per capita expenditure in rural, metro and urban India 
Cumulative distribution of anthropometric indicators against log per capita expenditure

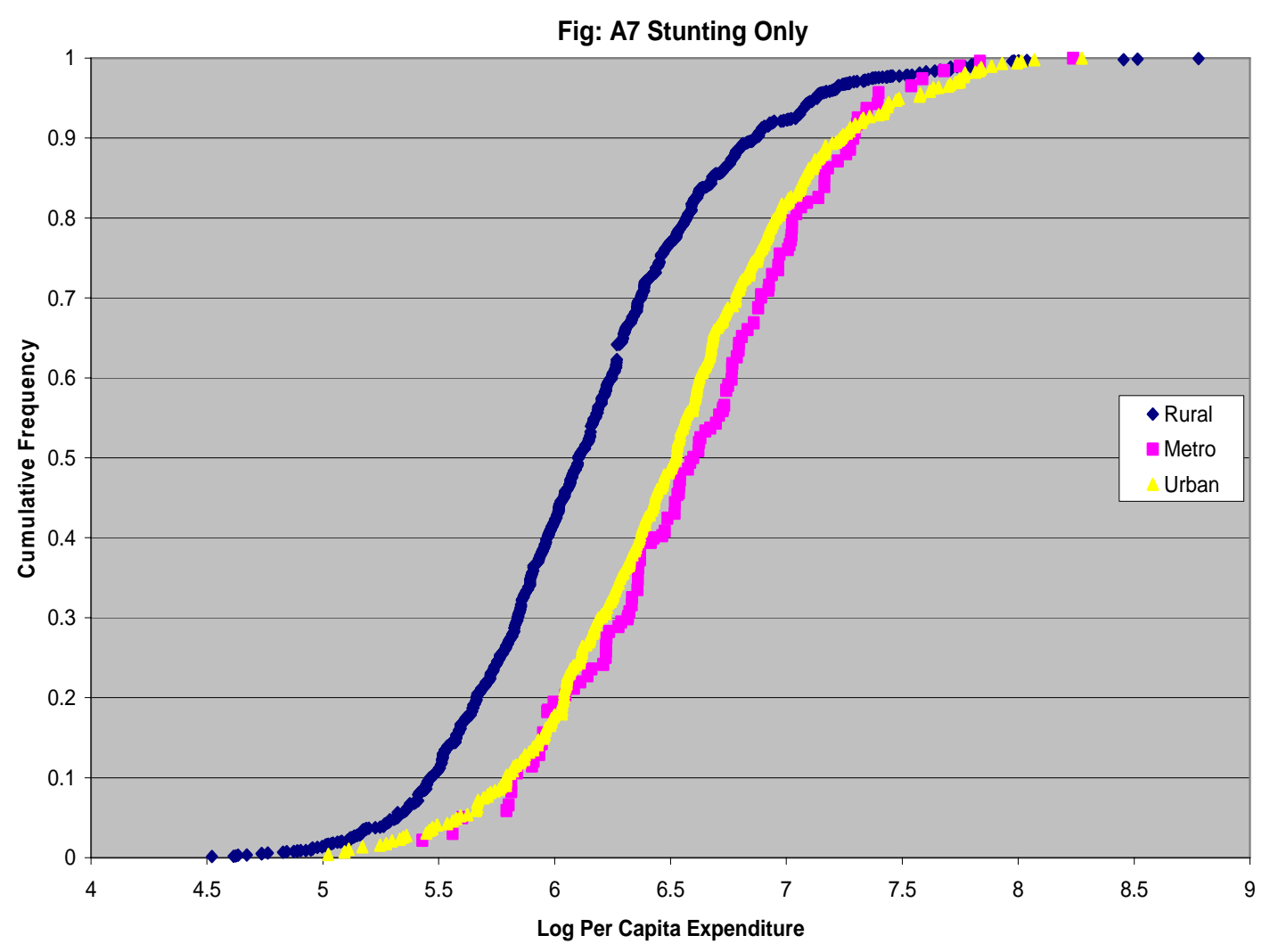

Figure A7: Cumulative distribution of stunting only against log per capita expenditure in rural, metro and urban India 
Cumulative distribution of anthropometric indicators against log per capita expenditure

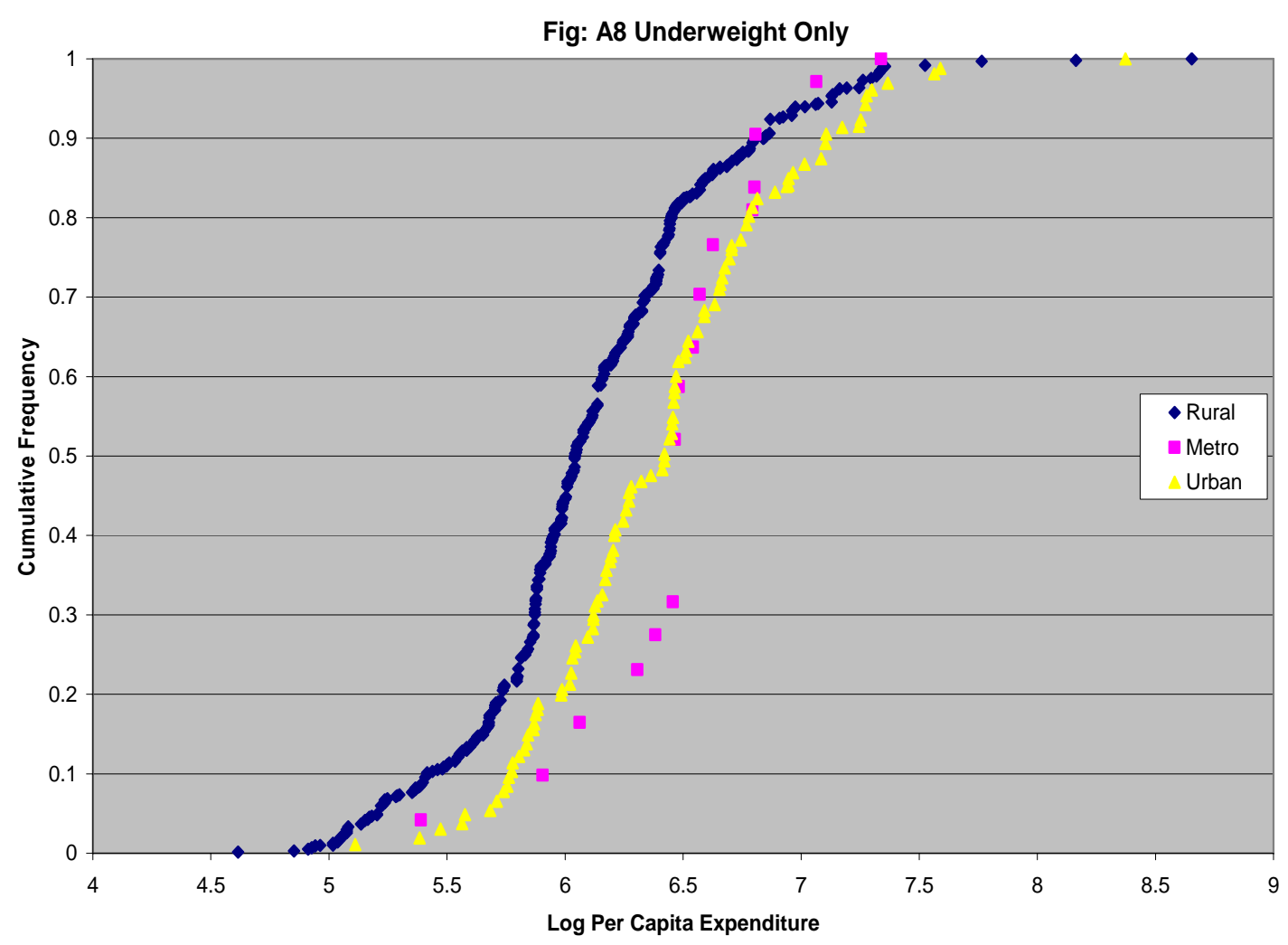

Figure A8: Cumulative distribution of underweight only against log per capita expenditure in rural, metro and urban India 
Cumulative Distribution of Anthropometric Indicators against log per capita expenditure

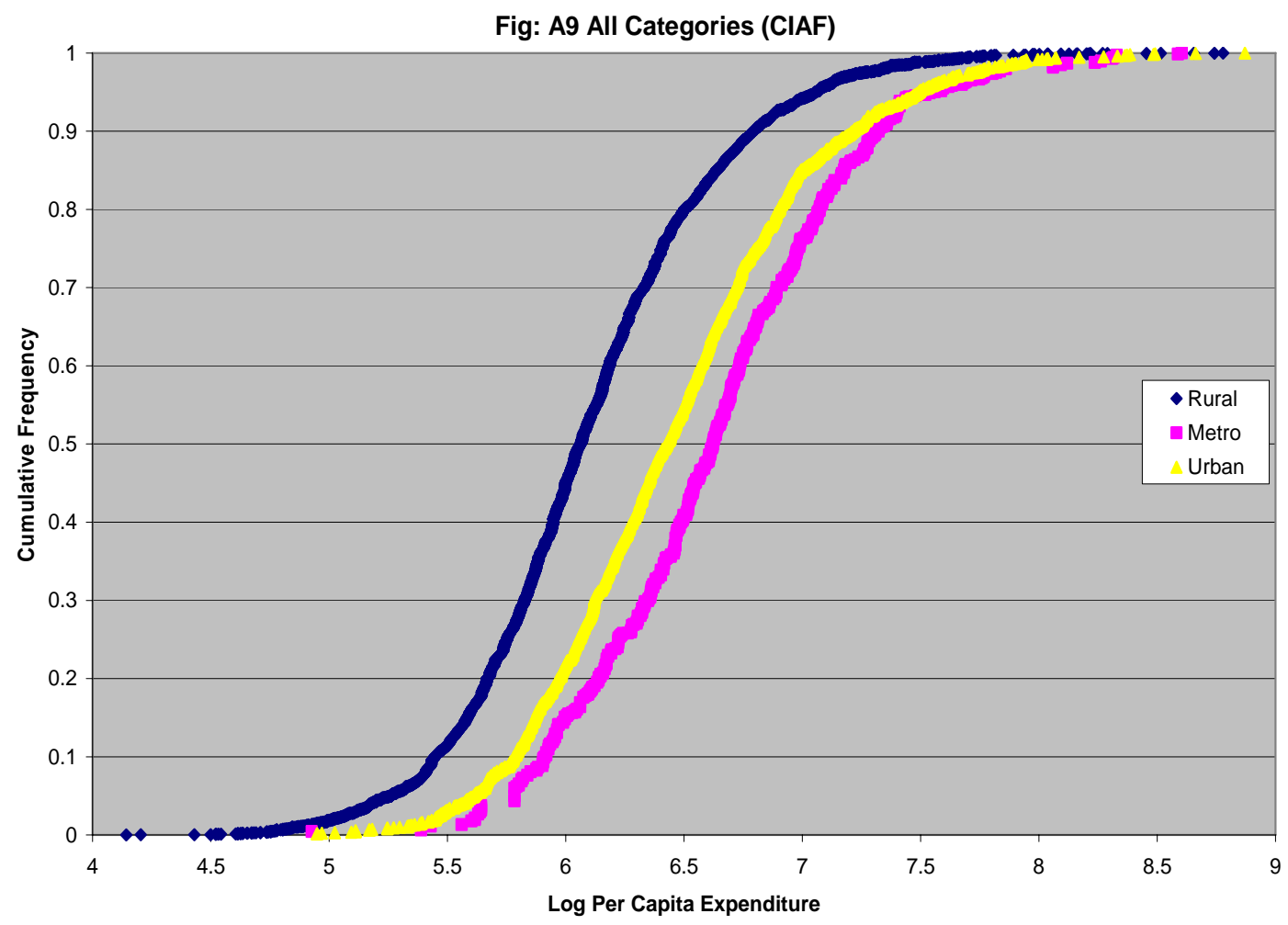

Figure A9: Cumulative distribution of CIAF against log per capita expenditure in rural, metro and urban India 
Table A.1

Definitions of Variables Used in the Analysis

\begin{tabular}{|c|c|}
\hline Variable & Definition \\
\hline \multicolumn{2}{|r|}{ Dependent variable } \\
\hline CIAF & Composite Index of Anthropometric Failure \\
\hline \multicolumn{2}{|c|}{ Explanatory variables } \\
\hline Age: Female Respondent & Age (in years) \\
\hline SC & $=1$ if social group is SC; 0 otherwise \\
\hline ST & $=1$ if social group is ST; 0 otherwise \\
\hline OBC & $=1$ if social group is OBC; 0 otherwise \\
\hline Others (reference) & Omitted group \\
\hline Gender: Household Head & $=1$ if household head is female; 0 if male \\
\hline Marital Status: Female Respondent & $=1$ if household head is married; 0 otherwise \\
\hline Years of education: Female Respondent & Number of years completed in education by household head \\
\hline Vent in kitchen & $=1$ if kitchen has vent; 0 otherwise \\
\hline Piped water & $=1$ if access to piped water; 0 otherwise \\
\hline Hand pump or tube-well & $=1$ if household has hand pump or tube-well; 0 otherwise \\
\hline Rural areas & $=1$ if Rural, 0 otherwise \\
\hline Urban metros & $=1$ if Metro, 0 otherwise \\
\hline Non-metro urban (reference) & $=1$ if Non-metro urban, 0 otherwise \\
\hline Marital Status Household Head: Married & $=1$ if household head is married; 0 otherwise \\
\hline Log PCME (IV) & Log of per capita monthly expenditure (predicted-) \\
\hline Log Price: rice $^{1}$ & Log Price of rice \\
\hline Log Price: wheat & Log Price of wheat \\
\hline Log Price: sugar & Log Price of sugar \\
\hline Log Price: kerosene & Log Price of kerosene \\
\hline Log Price: other-cereals & Log Price of other-cereals \\
\hline Log Price: cereal-product & Log Price of cereal-product \\
\hline Log Price: pulses & Log Price of pulses \\
\hline Log Price: meat & Log Price of meat \\
\hline Log Price: gur & Log Price of gur \\
\hline Log Price: edible oil & Log Price of edible oil \\
\hline Log Price: eggs & Log Price of eggs \\
\hline Log Price: milk & Log Price of milk \\
\hline Log Price: milk-product & Log Price of milk-product \\
\hline Log Price: vegetables & Log Price of vegetables \\
\hline Log Price: salt-spices & Log Price of salt-spices \\
\hline Log Price: tea-coffee-processed & Log Price of tea-coffee-processed \\
\hline Log Price: paan-tobacco & Log Price of paan-tobacco \\
\hline Log Price: fruits-nuts & Log Price of fruits-nuts \\
\hline
\end{tabular}

1. All prices are at the PSU level. Female respondent was typically female spouse. 